\title{
FORTUNA VITREA
}

Arbeiten zur literarischen Tradition zwischen

dem 13. und 16. Jahrhundert

Herausgegeben von

Walter Haug und Burghart Wachinger

Band 14 



\section{Kleinstformen der Literatur}

Herausgegeben von

Walter Haug

und Burghart Wachinger

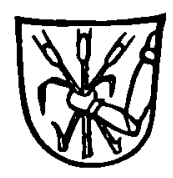

MAX NIEMEYER VERLAG

TÜBINGEN 
Gedruckt mit Mitteln aus dem Leibniz-Programm der Deutschen Forschungsgemeinschaft

Die Deutsche Bibliothek - CIP-Einheitsaufnahme

Kleinstformen der Literatur/ hrsg. von Walter Haug und Burghart Wachinger. - Tübingen : Niemeyer, 1994

(Fortuna vitrea ; Bd. 14)

NE: Haug, Walter [Hrsg.]; GT

ISBN 3-484-15514-0 ISSN 0938-9660

(C) Max Niemeyer Verlag GmbH \& Co. KG, Tübingen 1994

Das Werk einschließlich aller seiner Teile ist urheberrechtlich geschützt. Jede Verwertung außerhalb der engen Grenzen des Urheberrechtsgesetzes ist ohne Zustimmung des Verlages unzulässig und strafbar. Das gilt insbesondere für Vervielfältigungen, Übersetzungen, Mikroverfilmungen und die Einspeicherung und Verarbeitung in elektronischen Systemen. Printed in Germany.

Satz: pagina $\mathrm{GmbH}$, Tübingen

Druck: Algäuer Zeitungsverlag GmbH, Kempten

Buchbinder: Heinr. Koch, Tübingen 